\title{
STUDI ANALISIS ION LOGAM Hg(II) DENGAN ASAM TANAT SECARA SPEKTROFOTOMETRI ULTRAUNGU-TAMPAK
}

\author{
Fitria Ayu Lestari $^{1}$, R. Supriyanto ${ }^{1 *}$, Ni Luh Gede Ratna Juliasih ${ }^{1}$, Agung Abadi Kiswandono ${ }^{1}$ \\ ${ }^{1}$ Jurusan Kimia, FMIPA, Universitas Lampung, Bandar Lampung, 35141
}

\author{
fitriaayulestari046@gmail.com
}

\begin{tabular}{|l|}
\hline Artikel Info \\
\hline Diterima \\
tanggal \\
12.09 .2019 \\
Disetujui \\
publikasi \\
tanggal \\
31.10 .2019 \\
Kata kunci : \\
Asam tanat, \\
Hg, LoD, LoQ \\
\end{tabular}

\begin{abstract}
ABSTRAK
Telah dilakukan studi analisis ion logam $\mathrm{Hg}(\mathrm{II})$ dengan asam tanat secara spektrofotometri ultraungu-tampak. Studi ini dilakukan untuk mengetahui panjang gelombang maksimum kompleks $\mathrm{Hg}$ (II)-asam tanat pada $\mathrm{pH}$ optimum, konsentrasi optimum, volume optimum dan waktu kestabilan. Hasil penelitian menunjukan, bahwa panjang gelombang maksimum untuk kompleks $\mathrm{Hg}$ (II)asam tanat adalah $420 \mathrm{~nm}$ pada $\mathrm{pH}$ 9, dengan perbandingan stoikiometri variasi konsentrasi $\mathrm{Hg}(\mathrm{II})$ : asam tanat yaitu 1:4, dengan perbandingan stoikiometri variasi volume $\mathrm{Hg}(\mathrm{II})$ : asam tanat 1:1 dan mencapai waktu kestabilan setelah 40 menit. Validasi metode pembentukan kompleks $\mathrm{Hg}$ (II)-asam tanat diperoleh nilai $r$ sebesar 0,9995, nilai LoD dan LoQ yang diperoleh sebesar 0,00019 dan 0,00065 , nilai pesisi dengan $\%$ RSD sebesar $0,8732 \%$, serta nilai akurasi dengan $\%$ recovery yang diperoleh yaitu $99,45 \%$.
\end{abstract}

\section{ABSTRACT}

An analysis of $\mathrm{Hg}$ (II) metal ions with tannic acid was carried out by using ultraviolet-visible spectrophotometry. This study was aimed to determine the maximum wavelength of complex $\mathrm{Hg}$ (II)tannic acid at optimum $\mathrm{pH}$, optimum concentration, optimum volume and stabil time. The results showed that the maximum wavelength of complex $\mathrm{Hg}(\mathrm{II})$-tannic acid was $420 \mathrm{~nm}$ at $\mathrm{pH} 9$, with stoichiometric concentration of $\mathrm{Hg}(\mathrm{II})$ : tannic acid was $1: 4$, the stoichiometric volume of $\mathrm{Hg}(\mathrm{II})$ : tannic acid was 1:1, and the stability time was over 40 minutes. The validation method of complex $\mathrm{Hg}$ (II)-tannic acid meets the AOAC acceptance standard. The linearity with the r-value of 0.9995 , the LoD and LoQ was obtained 0.00019 and 0.00065 respectively. The precision value with \%RSD of $0.8732 \%$, and the accuracy value with the \%recovery obtained is $99.45 \%$.

\section{PENDAHULUAN}

Salah satu bentuk menurunnya kualitas lingkungan yakni meningkatnya konsentrasi bahan-bahan pencemar seperti logam berat. Logam berat umumnya bersifat racun terhadap makhluk hidup, meskipun dalam konsentrasi yang rendah (ppm ataupun ppb) salah satunya yaitu merkuri. Merkuri apabila terpapar oleh tubuh maka akan menyebabkan gangguan kesehatan pada system organ himgga kematian.

Penelitian mengenai logam $\mathrm{Hg}$ banyak dilakukan menggunakan metode spektrofotometri serapan atom uap dingin (SSA-UD). Metode ini memiliki beberapa kekurangan yaitu hanya dapat digunakan khusus untuk atomisasi logam $\mathrm{Hg}$, tidak dapat 
mendeteksi berbagai jenis $\mathrm{Hg}$ yang ada dalam sampel, dan membutuhkan biaya oprasional yang besar (Mona dkk., 2018). Metode alternatif untuk menganalisis logam $\mathrm{Hg}$ dapat dilakukan dengan metode spektrofotometri ultraungu-tampak. Metode ini telah menjadi metode analisis yang sangat signifikan di laboratorium modern. Metode ini memiliki keunggulan yakni bersifat fleksibel, sederhana, akurat, tidak membutuhkan waktu analisis yang lama, dan biaya oprasional yang dikeluarkan rendah (Zhou et al., 2018).

Analisis $\mathrm{Hg}(\mathrm{II})$ yang dapat dilakukan adalah dengan pembentukan $\mathrm{Hg}$ dengan ligan. Salah satu bahan alam yang dapat dimanfaatkan sebagai ligan dalam menganalisis ion logam $\mathrm{Hg}$ dengan cara pembentukan kompleks adalah asam tanat. Asam tanat bila ditinjau dari strukturnya merupakan senyawa yang memiliki pasangan elektron bebas, baik pada gugus keton (pada keadaan polimer) dan gugus hidroksil (ketika ditambahkan basa atau asam pada saat pengaturan $\mathrm{pH}$ ). Pasangan elektron bebas ini dapat didonorkan kepada ion logam $\mathrm{Hg}$ yang memiliki orbital kosong, sehingga asam tanat merupakan suatu ligan yang dapat mendonorkan pasangan elektron bebas kepada ion logam Hg (Supriyanto, 2011).

Penelitian ini bertujuan untuk mengembangkan metode analisis yang mengarah pada kimia ramah lingkungan (Green Chemistry) dengan memanfaatkan bahan alam sebagai ligan. Mendapatkan kondisi analisis optimum pembentukan kompleks $\mathrm{Hg}$ (II)-Asam tanat terhadap $\mathrm{pH}$, konsentrasi, dan volume serta mendapatkan waktu kestabilan kompleks $\mathrm{Hg}(\mathrm{II})$-Asam tanat. Melakukan validasi metode terhadap analisis kompleks $\mathrm{Hg}$ (II)-Asam Tanat secara spektrofotometer ultraungu tampak.

\section{METODE}

\section{Alat dan Bahan}

Alat utama yang digunakan dalam penelitian ini adalah instrument analisis Spektrofotometer Ultraungu Tampak Hitachi U-2010. Bahan yang digunakan adalah $\mathrm{HgCl}_{2}$ Industrial Grade, Asam Tanat Pro Analisis, dan $\mathrm{NaOH}$

\section{Prosedur}

$\mathrm{HgCl}_{2}$ dan Asam tanat ditimbang kemudian dilarutkan lalu dicampurkan kedalam Erlenmeyer kemudian ditambah dengan $\mathrm{NaOH}$ hingga membentuk Kompleks. Kompleks $\mathrm{Hg}$ (II)-asam tanat tersebut, kemudian diukur panjang gelombang maksimumnya dan absorbansinya. Kompleks tersebut divariasikan pHnya pada rentang 8-12, kemudian dilakukan penentuan stoikiometri dengan ion logam $\mathrm{Hg}(\mathrm{II})$ : asam tanat dengan perbandingan $1: 1,1: 2,1: 3,1: 4,1: 5$, dan penentuan volume ion logam $\mathrm{Hg}(\mathrm{II})$ dengan asam tanat yaitu 1:1, 
1:2, 1:3, 1:4, 1:5. Selanjutnya, dilakukan penentuan waktu kestabilan kompleks $\mathrm{Hg}(\mathrm{II})$-asam tanat pada keadaan optimum pada rentamh 0-60 menit. Tahap selanjutnya dilakukan validasi metode penelitian dengan mengukur linearitas, LoD dan LoQ, presisi dan akurasi sesuai dengan metode AOAC.

\section{HASIL DAN PEMBAHASAN}

\section{Penentuan Panjang Gelombang Kompleks Hg(II)-Asam Tanat}

Panjang gelombang maksimum kompleks ditentukan untuk mengetahui nilai panjang gelombang komponen menyerap maksimum terhadap sinar monokromatis yang digunakan. Hasil dari penelitian ini diperoleh panjang gelombang maksimum kompleks $\mathrm{Hg}(\mathrm{II})$-asam tanat $420 \mathrm{~nm}$ dengan absorbansi sebesar 0,262 $\mathrm{nm}$.

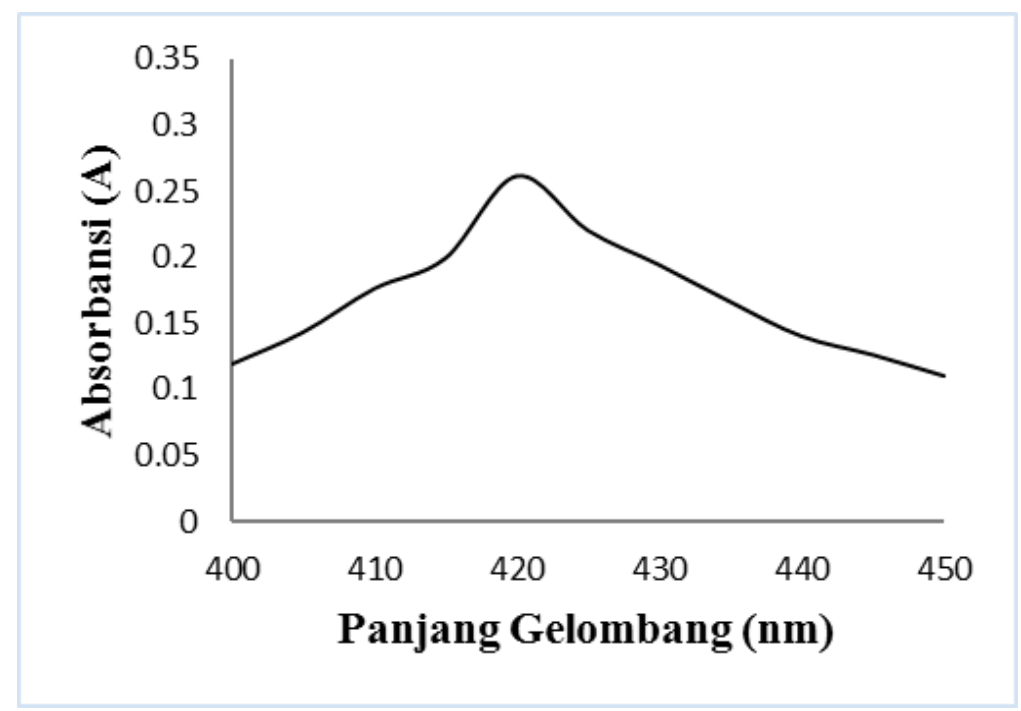

Gambar 1. Panjang Gelombang Hg(II)-Asam Tanat

Munculnya panjang gelombang pada $420 \mathrm{~nm}$ menunjukkan adanya pergeseran batokromik , yaitu pergeseran puncak absorbsi ke arah panjang gelombang yang lebih besar. Adanya pergeseran batokromik disebabkan karena struktur senyawa kompleks tersebut memiliki gugus kromofor (ikatan $\mathrm{C}=\mathrm{O}$ ) dan ausokrom (gugus $\mathrm{OH}$ ) yang berasal dari ligan asam tanat. Gugus-gugus tersebut yang menyebabkan senyawa kompleks $\mathrm{Hg}$ (II)-asam tanat dapat menyerap cahaya pada daerah tampak. 


\section{Pengaruh Variasi pH pada Pembentukan Kompleks Hg(II)-Asam Tanat}

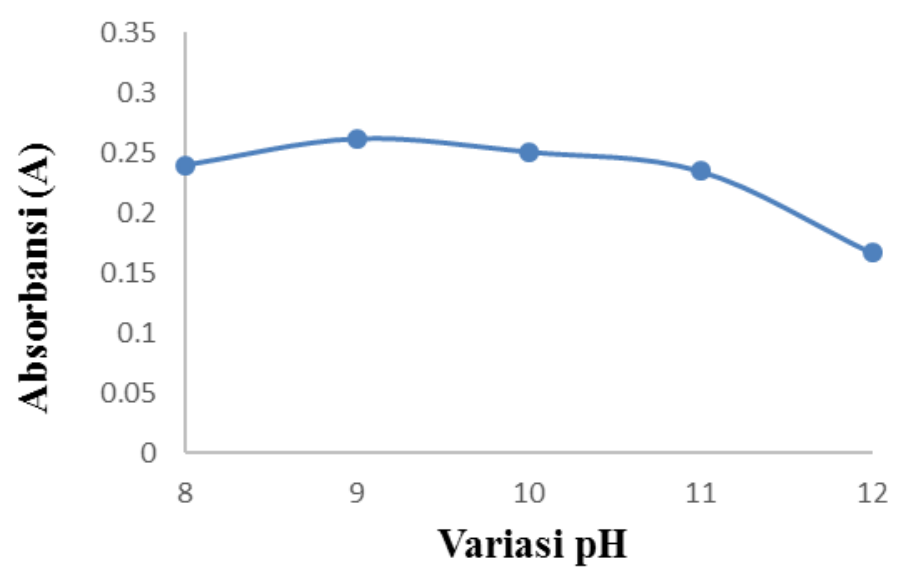

Gambar 2. Pengaruh Variasi Ph terhadap Absorbansi

Gambar 2 menunjukkan bahwa pembentukan kompleks $\mathrm{Hg}$ (II)-asam tanat tersebut optimum pada $\mathrm{pH} 9$ dengan absorbansi 0,262. Hal ini menujukkan bahwa ion $\mathrm{Hg}$ (II) dalam kondisi optimum dan asam tanat (ligan pada senyawa polifenol) cenderung terionisasi sempurna dengan melepas ion $\mathrm{H}^{+}$dan muatan pada ligan senyawa polifenol menjadi negatif sehingga terjadi interaksi elektrostatik antara ligan dan ion $\mathrm{Hg}(\mathrm{II})$. Data tersebut menunjukkan bahwa pada pH 10,11 dan 12 absorbansi semakin menurun. Hal ini dikarenakan pada $\mathrm{pH}$ yang terlalu tinggi konsentrasi dari ion $\mathrm{OH}^{-}$akan meningkat sehingga memungkinkan terjadinya pertukaran antara ion $\mathrm{OH}^{-}$dengan ligan (Lestari et al., 2014), sehingga mempengaruhi interaksi ligan dengan ion $\mathrm{Hg}$ (II) dalam larutan yang menyebabkan kompleks yang dihasilkan kurang stabil.

Ion $\mathrm{Hg}(\mathrm{II})$ dapat bertindak sebagai ion pusat (asam lewis) pengkelat untuk bereaksi dengan berbagai donor elektron karena keberadaan orbital kosong $6 \mathrm{~s}^{0} 6 \mathrm{p}^{0}$ dalam konfigurasi elektronnya sehingga ia dapat menerima 4 pasang elektron dari suatu ligan. Di sisi lain, hidroksil fenolik dari asam tanat mempunyai pasangan elektron bebas yang dapat memainkan peran donor yang kuat, yang memiliki afinitas tinggi terhadap ion logam pusat. Hidroksil fenolik bermuatan negatif tersebut bertindak sebagai ligan untuk berikatan dengan satu ion $\mathrm{Hg}$ (II) sehingga terbentuk senyawa kompleks $\mathrm{Hg}$ (II)-asam tanat yang stabil (Huang et al., 2009). Bentuk geometri kompleks $\mathrm{Hg}(\mathrm{II})$ - asam tanat. 
Penentuan Stoikiometri Pembentukan Kompleks Hg(II)-Asam Tanat dengan Variasi Konsentrasi Hg(II) : Asam Tanat (mM)

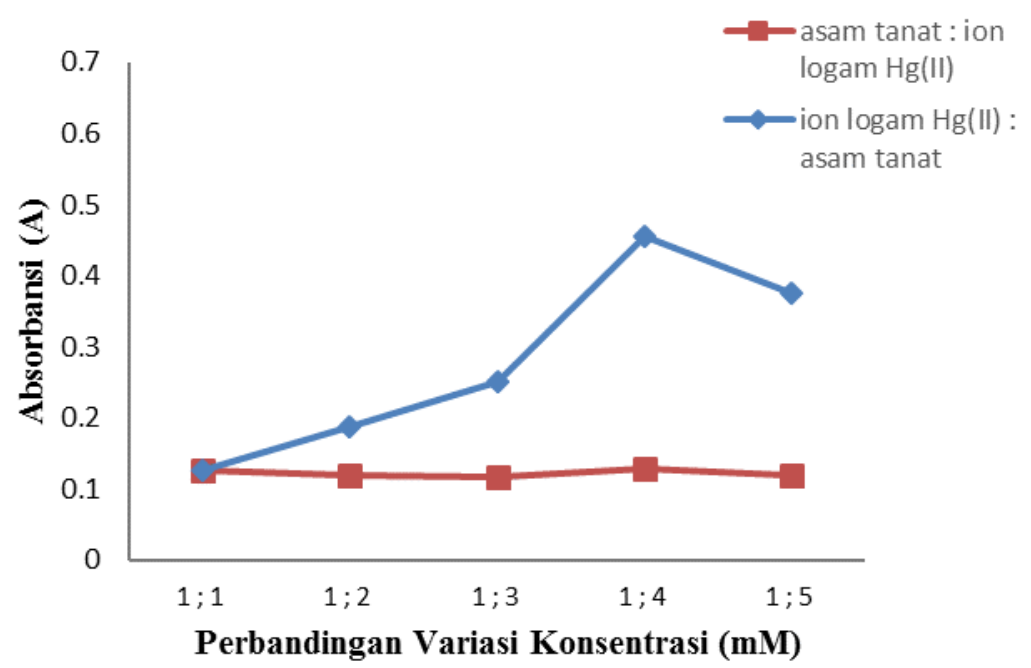

Gambar 3. Kurva Perbandingan Variasi Konsentrasi Hg(II) : Asam Tanat dan Asam Tanat :

$\mathrm{Hg}$ (II) Terhadap Absorbansi Kompleks Hg(II)-Asam Tanat<smiles>O=C(O)c1cc(O)c(O)c(O[Ga](Oc2cc(C(=O)O)cc(O)c2O)Oc2cc(C(=O)O)cc(O)c2O)c1</smiles>

Gambar 4. Struktur Tetrahedral kompleks Hg(II)-Asam Tanat 


\section{Penentuan Stoikiometri Pembentukan Kompleks Hg(II)-Asam Tanat dengan Variasi} Volume Hg(II)-Asam Tanat (mL)

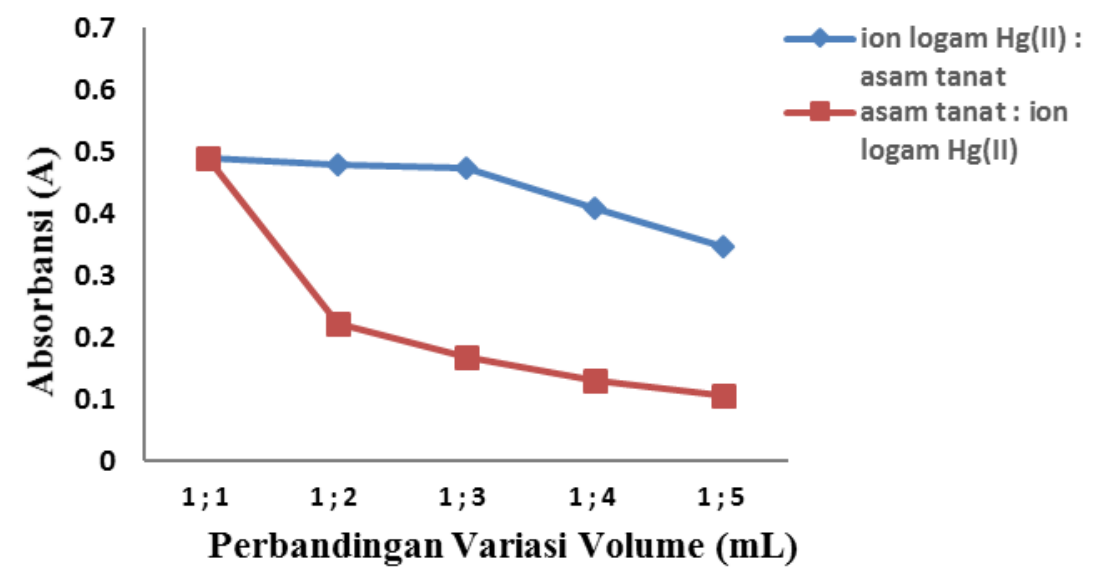

Gambar 5. Kurva Variasi Volume Hg(II) : Asam Tanat dan Asam Tanat : Hg(II) Terhadap Absorbansi Kompleks Hg(II)-Asam Tanat

Berdasarkan gambar 5, absorbansi optimum yang diperoleh terlihat pada perbandingan volume ion logam $\mathrm{Hg}(\mathrm{II})$ dan asam tanat yaitu 1:1.

\section{Penentuan Waktu Kestabilan Kompleks Hg(II)-Asam Tanat}

Kestabilan optimum adalah waktu yang dibutuhkan untuk mendapatkan absorbansi yang tidak mengalami perubahan yang terlalu signifikan. Hasil dari penelitian ini menunjukkan absorbansi kompleks sudah mencapai keadaan stabil setelah menit ke 40-60, pada menit ini terlihat absorbansi yang hampir sama dan juga tampak warna orange yang stabil.

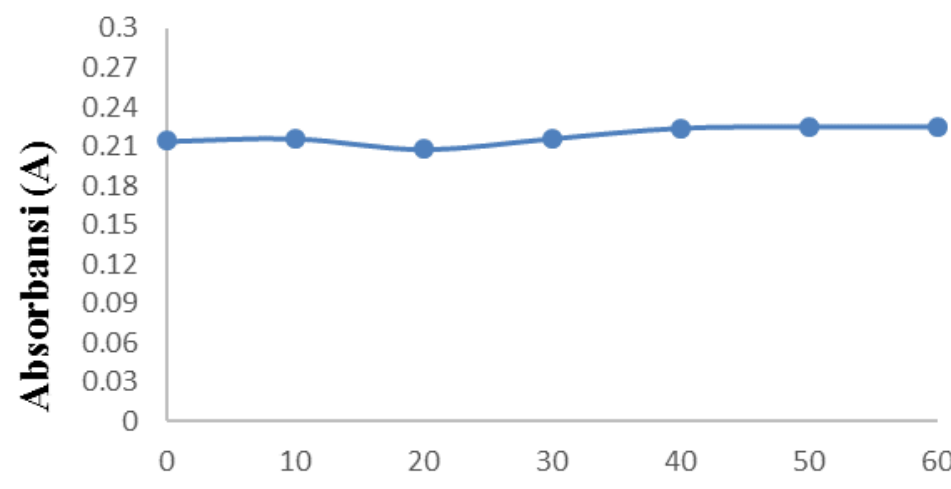

Waktu Kestabilan (Menit)

Gambar 6. Kurva Waktu Kestabilan Kompleks Hg(II)-Asam Tanat 


\section{Validasi Metode}

\section{Linearitas}

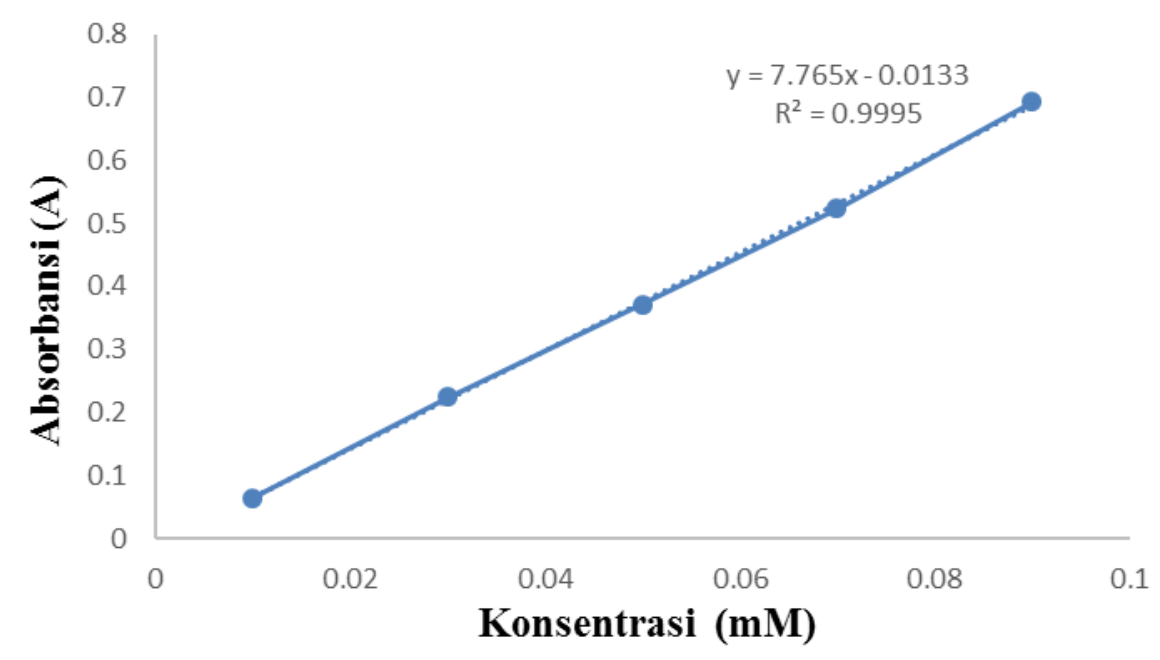

Gambar 7. Kurva Linearitas

Berdasarkan Gambar 7 dapat diketahui persamaan garis lurus yang diperoleh adalah y $=(-0,0133)+7,765 \mathrm{x}$ dengan koefisien korelasi sebesar 0,9995. Nilai koefisien korelasi yang diperoleh dikatakan baik karena memenuhi persyaratan keberterimaan yaitu > 0,99 (AOAC, 2002). Nilai $0,9995<r^{2}<1$ menyatakan bahwa hasil data linearitas valid dan terdapat korelasi yang sangat kuat antara konsentrasi dan absorbansi yang dihasilkan.

\section{KESIMPULAN}

Larutan asam tanat dapat membentuk kompleks dengan ion $\mathrm{Hg}$ (II) dengan memberikan warna kuning tua bening, Kondisi optimum pembentukan kompleks $\mathrm{Hg}$ (II)Asam tanat diperoleh pada $\mathrm{pH}$ 9, perbandingan konsentrasi $\mathrm{Hg}(\mathrm{II})$ : asam tanat 1:4, perbandingan volume $\mathrm{Hg}(\mathrm{II})$ : asam tanat 1:1 pada panjang gelombang $420 \mathrm{~nm}$ dan stabil pada menit ke-40. Metode analisis kompleks $\mathrm{Hg}$ (II)-Asam tanat secara spektrofotometer ultraungu-tampak sudah memenuhi kriteria metode yang valid menurut AOAC, dengan nilai linearitas 0,9995; nilai presisi (\%RSD) 0,8732; nilai akurasi (\%recovery) 99,45\%; LoD 0,00019 dan LoQ 0,00065. 


\section{DAFTAR PUSTAKA}

Huang, X., Liao, X., and Shi, B. 2009. Hg(II) Removal From Aqueous Solution by Bayberry Tannin-Immobilized Collagen Fiber. J. Hazard. Mater. 170: 1141-1148.

Lestari, I., Frida, A., dan Sanova, A. 2014. Sintesis dan Karakterisasi Senyawa Kompleks Logam Kadmium(II) dengan Ligan Kupferon. Jurnal Penelitian Universitas Jambi Seri Sains. 16(1): 1-8.

Mona, R. K., Pontoh, J., Paulina, V., dan Yamlean, Y. 2018. Analisis Kandungan Merkuri (Hg) Pada Beberapa Krim Pemutih Wajah Tanpa Ijn BPOM yang Beredar di Pasar 45 Manado. Pharmacon. 7(3): 2302-2493.

Supriyanto, R. 2011. Studi Analisis Spesiesi Ion Logam Cr(III) dan Cr(IV) dengan Asam Tanat dari Ekstrak Gambir Menggunakan Spektrofotometri UV-Vis. J. Sains. 17(1): $35-42$.

Zhou , F., Li, C., Zhu, H., and Li, Y. 2018. Simultaneous Determination of Trace Metal Ions in Industrial Wastewater Based on UV-Vis Spectrometry. Optik. 176: 512-517. 